\title{
Zur Bedeutung von H. Manns Untertan und F. Saltens Lueger-Essay für das Wechselverhältnis der deutschen und österreichischen Literatur
}

\section{Hansgerd Delbrück}

I.

Arthur Schnitzler las Heinrich Manns Roman Der Untertan, wie in seinem Tagebuch festgehalten ist, in den Weihnachtstagen 1918. Er war so beeindruckt, daß er sein Urteil in das eine Wort zusammenfaßte: "Außerordentlich" - jedoch mit der bedauernden Einschränkung: "mehr caricaturistisch im Detail als satirisch im großen." 1 Dem Buch fehle zur großen Satire die Voraussetzung, weil es in ihm "allzuviel $\mathrm{Haß}$ und Einseitigkeit" gebe. Ganz offensichtlich war dieses künstlerische Verdikt politisch motiviert, denn er hielt es für durchaus unwahrscheinlich, daß solche Gestalten wie Diederich Heßling - "eine große Gestalt in ihrer Jämmerlichkeit" - im demokratischen Deutschland fehlen würden. Schnitzlers Skepsis war also in erster Linie gegen die Deutschen gerichtet, die sich doch nie ändern würden, in welchem System auch immer. Doch entdeckt man bei genauerem Hinsehen in Schnitzlers für Fairness plaidierendem Urteil auch deutliche Spuren eines nicht zu unterdrückenden promonarchistischen Vorurteils. Heinrich Mann hätte, so Schnitzlers Überlegung, kein antimonarchistisches Buch schreiben dürfen, solange es nicht gleichzeitig auch in Frankreich ein literarisches Werk gegen die Mißstände der Demokratie gab: "wo die Politik um Poincaré doch eine mindestens so scheußliche Sache war wie die um Wilhelm;- in der immerhin eine Idee zu spüren war - vielleicht von Verfolgungswahn genährt - wenn es Wahn war!-" (Ebd.) $)^{2}$ Am 15. 1. nannte er in einem Brief an den gemeinsamen

\footnotetext{
${ }^{1}$ Arthur Schnitzler: Tagebuch 1917-1919, Wien 1985, S. 212.

${ }^{2}$ Auch in seinem Brief an Heinrich Mann vom 3. 1. 1919, in dem er den Untertan (damals noch Unterthan) zunächst rühmte als "kühn im Entwurf, unerbittlich in der Durchführung, von wildestem Humor und mit unvergleichlicher Kunst erzählt", folgte auf die Feier Kritik; statt Heinrich Mann direkt und im Detail des einseitigen Antimonarchismus zu zeihen, rief er hier diplomatisch den lieben Gott zur Ordnung: "- wenn der liebe Gott nur halb
} 
Verleger Samuel Fischer die künstlerische Leistung des Romans erneut "außerordentlich", doch sei ihm der Roman deshalb "in seinem innersten Wesen keineswegs durchaus sympathisch". Sympathischer nämlich waren ihm Thomas Manns konservative Betrachtungen eines Unpolitischen, und es war ihm auch wiederholt passiert, eine Bemerkung, die er "gesprächsweise Heinrich gegenüber hatte fallen lassen, ein paar Stunden nachher fast wörtlich in einem Aufsatz von Thomas wiederzufinden." Trotzdem spielte er nun gegenüber seinem Verleger nicht einfach den Monarchisten Thomas gegen den Demokraten Heinrich aus. Da sie glücklicherweise beide "als Dichter das Wesen der Geschichte zu tief empfinden, um ja auch dort, wie sie es gerne wollten, wirklich Politiker sein zu können," habe ihr politischer Ehrgeiz, obwohl er sich bis in ihre Dichtung erstreckte, ihr künstlerisches Verdienst nicht ernsthaft gefährden können. ${ }^{3}$

Schnitzler wollte also das politische Engagement, das Heinrich Mann mit dem Untertan verfolgte, nicht etwa fortinterpretieren, sondern nur soweit eben möglich entschuldigen. Heinrich Mann selber ging dagegen viele Jahre später in seiner Autobiographie, die er unter dem Titel Ein Zeitalter wird besichtigt im letzten Jahr des Zweiten Weltkriegs beendete, aber erst 1949 veröffentlichte, erheblich weiter und erklärte, er habe die politische Nutzanwendung aus dem Untertan in Wahrheit den Lesern

so gerecht ist als der Präsident Wilson zu sein es sich einbildet, so muß er dafür sorgen, daß auch in den übrigen Ländern, vor allem in Frankreich, Dichter von Ihrem Genie auferstehen, die allein fähig wären die große Angelegenheit der Menschheit künstlerisch wieder ins Gleichgewicht zu bringen." (Briefe, 1913-1931, hrsg. Peter Michael Braunwarth, Frankfurt a.M. 1984, S. 169) - Es wirkt bemüht und künstlich, wie Schnitzler aus politischen Gründen nicht nur versucht, dem Roman die Qualität großer Satire abzusprechen, sondern in bezug auf den Roman den Begriff der Satire überhaupt vermeidet. Zur Kennzeichnung des Romans ist "wildester Humor" schwerlich besser geeignet als der sich aufdrängende Begriff politischer Satire. Zur Frage der Berechtigung des Satire-Begriffs vgl. erneut Hans Wißkirchen, "Heinrich Mann, 'Der Untertan': Epochenroman oder Satire?" in: Heinrich-Mann-Jahrbuch, Bd. 11, 1993, S. 57-73. Wißkirchens These, daß der Roman nicht nur Satire sei, wird man zustimmen können. Seine naive Deutung des Romanschlusses zeugt jedoch umgekehrt von einem bedauerlichen Mangel an Verständnis für die satirische Intention des Untertans: "[Heßling] ist am Ende wieder zufrieden und mit dem Tod des alten Buck gibt es niemanden mehr in der kleinen Stadt, der ihm den Aufstieg zu wirtschaftlichen und politischen Höhen streitig machen kann." (S. 68).

${ }^{3}$ Briefe, 1913-1931, S. 171-172. 
überlassen: "War ich ein Kämpfer? Ich gestaltete, was ich sah, und suchte mein Wissen überzeugend, wenn es hoch kam, auch anwendbar zu machen." 4 Schnitzler hat hier jedenfalls richtiger geurteilt. Das politische Engagement zeigt sich am deutlichsten am Romanende, auf das Der Untertan aber natürlich von Anfang an angelegt war.

Die Gewißheit des sich selbst zum Untergang verurteiltenden Kaiserreichs wird im Roman gleich zu Beginn moralisch so begründet, daß es seinen Aufstieg auf Kosten der Liberalen erreichte. Entsprechend beginnt der politische Aufstieg Heßlings damit, daß er die Liberalen in Deutschland als Verlierer einstuft. Zwar versichert er zu Beginn seiner Karriere dem alten Buck, der über Jahrzehnte der Verwaltung von Heßlings Vaterstadt Netzig vorgestanden und Heßlings Vater zu dem für die Papiermühle nötigen Wasser verholfen hat, er selber sei "selbstverständlich durchaus liberal." ${ }^{5}$ Doch schon auf dem Nachhauseweg verrät er dieses Versprechen mit der Entscheidung, daß er sich zur Wahrung seiner Interessen umgehend von Buck lösen müsse, weil der "bloß noch eine Vogelscheuche" sei, die ihn bei den wahrhaft Mächtigen kompromittiere. (91) Am Ende des Romans hat er es dann geschafft, den alten Liberalen Buck zum Rücktritt von seinem Amt als Stadtrat zu zwingen. (328) Das sieht aus wie ein Endsieg, und doch sieht Heßling gleich darauf ganz plötzlich und unerwartet für sich die Notwendigkeit eines Arrangements mit Gott, als kämpfte der auf der anderen Seite. Es ist die Stelle, als er während der Einweihung des Kaiser Wilhelm-Denkmals, bei der er zugleich für dessen geistige Urheberschaft mit dem ihm vom Kaiser verliehenen Wilhelmsorden geehrt werden soll, in einer Rede schmettern und donnern möchte, dabei aber von einem Gewitter überrascht wird, das ihn stumm macht und unter das Rednerpult treibt. Verschreckt verdächtigt er das Gewitter als den von ganz oben, also von Gott selbst gewollten Umsturz, der ihn samt

${ }^{4}$ Heinrich Mann: Ein Zeitalter wird besichtigt, Hamburg 1980, S. 156. Seine Äußerungen über sein Wirken in der Weimarer Republik klingen ähnlich und doch entschiedener, da sie ohne die Frageform auskommen: "Eingestanden sei, daß ich mich nicht wirklich als einen Kämpfer fühlte. Dafür durchschaute ich zu deutlich die Vergeblichkeit des Kampfes - und begleitete meine eigenen moralistischen Übungen mit dem Lächeln des Zweifels, das allein sie mir selbst erträglich machte. Oft genug erging ich mich ironisch, um mir und den Lesern einen guten Sonntag zu verschaffen." (S. 132).

${ }^{5}$ Heinrich Mann: Der Untertan, München 1980, S. 87. 
dem ganzen Kaiserregime hinwegfegen soll. Freilich endet das Gewitter ebenso plötzlich, wie es begonnen hat, so daß ihm das glimpfliche Ende unmotiviert scheint; und gleich darauf das eigene Überleben als ein Streich, den er seinerseits dem Himmel spielen konnte, so daß er ihm seinen Wilhelmsorden hinhält und "Ätsch" sagt. Und da das Gewitter so offensichtlich noch nicht "der Ernstfall" gewesen war, hält er es für nur recht und billig, daß es in der Fleischhauergasse, durch die er auf seinem Nachhauseweg kommt, statt seiner den alten Liberalen Buck getroffen hat. Sein Instinkt treibt ihn, das Haus des Sterbenden zu betreten, um als dessen politischer Erbe seine Besitzansprüche zu sichern.

Dort aber kommt es dann zur letzten und entscheidenden Entlarvung Heßlings in einer Szene, die sich nicht mehr nur zwischen ihm und Gott abspielt, der soeben scheinbar ungerührt sein "Ätsch" hingenommen hatte. Nein, es gibt nun Zeugen, die trotz mangelnder Einsicht in die wirklichen Zusammenhänge den Auftritt Heßlings angemessen kommentieren können. Und zwar so, daß die Szene für Heßling zur Fortsetzung und zum korrigierenden Nachspiel jener metaphysischen Auseinandersetzung mit Gott wird. Als nämlich der alte Buck im selben Moment stirbt, in dem er Heßling zur Tür hereinkommen sieht, ist sich die älteste Schwiegertochter sicher, daß Buck nicht nur an Altersschwäche stirbt: "Er hat den Teufel gesehen!" Heßling fühlt sich angesprochen - und tritt den Rückzug an. Als sie langsam aufsteht und die Tür schließt, ist er "schon entwichen."

So wird dem Leser mit dem Schlußsatz des Romans unmißverständlich zu verstehen gegeben, daß der Untergang, den Heßling mit dem Gewitter für sich selbst wie für das Kaiserreich herbeigekommen glaubte, nur vorläufig ausgesetzt war. Das Kaiserreich wird und muß mitsamt seinen es tragenden Untertanen, die vom Ende des Liberalismus profitieren wollen, sich von selbst verabschieden, wenn - und nur wenn - ihre teuflischen Machenschaften entlarvt sind.

Heinrich Mann wollte also wirklich, wenn er es auch später nicht mehr wahrhaben mochte, mit der Entlarvungstaktik des Romans nach Kräften zum Untergang des deutschen Kaiserreichs beitragen. Daß er dieses politische Engagement dann leugnete, wird jedoch verständlich, wenn man daran denkt, wie berechtigt Schnitzlers Skepsis gegenüber der Hoffnung war, die Heinrich Mann an das Ende des Kaiserreichs knüpfte. Gewiß 
würde heute niemand mehr Schnitzler in der promonarchistischen Kritik folgen, Heinrich Mann habe sich mit dem Roman unzulässig für ein demokratisches System nach dem Vorbild Frankreichs eingesetzt. Für Deutschland war das kommende Problem nicht die Demokratie, sondern deren Zerstörung durch das Naziregime. Hier aber konnte Heinrich Mann - und es wird gleich darauf zurückzukommen sein - schlecht für sich in Anspruch nehmen, mit seinem Roman bereits so vorausschauend gegen das Heraufkommen des Naziregimes wie für den Untergang des Kaiserreichs gekämpft zu haben. So zog er sich statt dessen auf die stolze Feststellung zurück, er habe mit dem Roman die Fähigkeit bewiesen, die Zukunft im voraus zu erraten, und zwar nicht nur die bevorstehende Niederlage des deutschen Kaiserreichs. Denn er habe auch schon den späteren Faschismus dokumentiert, "wenn man die Gestalt des 'Untertan' nachträglich betrachtet." (131) Er fügte hinzu: "Als ich sie aufstellte, fehlte mir von dem ungeborenen Faschismus der Begriff, und nur die Anschauung nicht." (Ebd.)

Die Behauptung, daß er die Niederlage des Kaiserreichs vorausgesagt hatte, war zweifellos richtig. Die Frage ist nur, unbeschadet der auch von Schnitzler mit Recht hervorgehobenen ganz außerordentlichen Verdienste des Untertans, wie weit der Stolz auf die Voraussage des Faschismus wirklich gerechtfertigt war. Da wir davon ausgehen dürfen, daß Heinrich Mann unter dem Begriff auch und vor allem die Gewalterrschaft der Nazis subsummieren wollte, scheint es angemessen zu fragen, welchen Stellenwert im Untertan der Antisemitismus hatte. ${ }^{6}$

${ }^{6}$ Interessant sind in diesem Zusammenhang die in Ein Zeitalter wird be. sichtigt versammelten Kommentare zu Schnitzlers Professor Bernhardi. Niemals, so erklärt Heinrich Mann, sei es das Ziel des Wiener Kollegen gewesen, in die Wirklichkeit einzugreifen, nicht einmal in Professor Bernhardi, und er belegt das nicht etwa mit einem einschlägigen biographischen Zitat, wie es sich etwa aus Schnitzlers Brief an Charmatz vom 4. Januar 1913 gewinnen läßt (vgl. Janz [Anm. 8], S. 108), sondern anhand der Rolle des Antisemitismus im Stück selbst: "Sein 'Professor Bernhardi' wollte den Antisemitismus nicht vernichten, er zeigte ihn in seinem düsteren Nichts." (S. 166) Da Professor Bernhardi gleichwohl das einzige Drama gewesen sei, in dem Schnitzler sich je "empört" habe, müsse es sich bei diesem Stück gleichsam um eine Empörung wider Willen gehandelt haben, eine Art Kunstfehler, der auf einer Überschätzung des Antisemitismus beruhte: "Der Antisemitismus, dieser steckengebliebene Sozialismus des 'dummen Kerls von Wien', wie man zur Zeit des Bürgermeisters Lueger sagte, ist endlich doch die ganze - die ganze - geistige Grundlage einer versuchten 
Tatsächlich spielt der Antisemitismus für die Handlung eine wichtige Rolle. Mehr noch als in Schnitzlers satirischer Komödie Professor Bernhardi, die zwei Jahre vor der Fertigstellung des Untertans beendet wurde, als Folge der Zensur aber erst nach dem Ersten Weltkrieg aufgeführt werden konnte, zeigt Der Untertan den Antisemitismus als eine gleichsam flächendeckende, selbstverständliche Gegebenheit. Ausgangspunkt des für den Roman zentralen Gerichtsprozesses ist die von dem menschenfreundlichen Fabrikbesitzer Lauer in einem Lokal nur gegenüber Freunden geäußerte und also privat gemeinte Empörung darüber, daß ein Arbeiter von einem Wachtmeister nicht etwa aus Versehen, sondern "mit behördlicher Billigung" erschossen wurde. (107) Lauer versteigt sich nach dem Genuß von Alkohol zu der umstürzlerischen Feststellung, es fehle der herrschenden Kaste, die da gerade erst wieder einen Mord an einem Arbeiter zu verantworten hatte, offensichtlich an Legitimität zur Vorherrschaft, da sie den anderen Klassen nichts mehr voraus habe: "Nicht einmal die Rasse... Denn sie sind ja alle verjudet, die Fürstenhäuser einbegriffen." (111) Es ist diese Anschuldigung, derentwegen der gleichfalls vom Alkohol beflügelte Diederich Heßling, der titelgebende Untertan des Romans, der vom Nebentisch aus zugehört hat, gegen Lauer Anzeige wegen Majestätsbeleidigung erstatten will. Heßling selber möchte am nächsten Morgen in nüchternem Zustand seine Absicht lieber vergessen. Doch kommt es trotzdem zum Prozeß, weil ausgerechnet der jüdische

Welteroberung geworden." Heinrich Mann sieht sich deshalb berechtigt, Schnitzler an dieser Stelle eine nach den Erfahrungen des Holocaust ganz unwahrscheinliche thetorische Frage in den Mund zu legen: "Wozu dann Empörung? dürfte Schnitzler jetzt fragen." Es geht hier aber natürlich nicht darum, wie Schnitzler, wäre er im Jahre der Veröffentlichung von Ein Zeitalter wird besichtigt noch am Leben gewesen, auf die ihm unterstellte Frage reagiert hätte. Deutlich wird vielmehr, daß Heinrich Mann damals offenbar noch keine volle Information über den Holocaust hatte. So konnte er sich in der positiven Bewertung der von Schnitzler in Professor Bernhardi gezeigten Empörung über den Antisemitismus darauf beschränken, sie als Beweis dafür zu sehen, daß Schnitzler an den "öffentlichen Dingen" offenbar im Sinne der politischen Zustände verstanden - "hilfloser, wenn nicht tiefer" gelitten habe als er selbst. (S. 169) Angesichts dieses neu eingeführten Wertbegriffs des Leidens verliert folgerichtig die Frage nach dem Sinn der Entscheidung für oder gegen politisches Engagement ein Gutteil an Relevanz: "Kampf allein tut es nicht, was bleibt denn von den Kämpfen. Fortzuleben verdienen die schönen Werke und fordern, daß ihrer gebrechlichen, bedrohten Ursprünge gedacht wird. Ich ehre Sie, lieber Arthur Schnitzler." (Ebd.) 
Gerichtsassessor Jadassohn Heßling zur Ordnung ruft und auf der Einreichung der Anklage besteht. Jadassohn nämlich hat am Vorabend in der Kneipe mit Heßling gezecht, war somit Zeuge des Vorfalls und erhofft sich von dem Prozeß einen Vorteil für seine Karriere, weil er da aufgrund der zufälligen Abwesenheit des Staatsanwalts dessen Stelle einnehmen kann.

Majestätsbeleidigung ist hier der Sache nach von Heßling wie von Jadassohn - und schließlich vom Gericht selbst - als der Versuch definiert, dem deutschen Kaiser jüdisches Blut zu unterstellen. So läuft die Majestätsbeleidigung indirekt auf Unterstellung mangelnden Antisemitismus bei den Fürsten heraus, die durch ein höheres Maß von Antisemitismus vor der "Verjudung" bewahrt worden wären. Aus der Perspektive derer, die den deutschen Kaiser gegen solche Nachrede glauben schützen zu müssen, erscheint der Antismistismus damit umgekehrt als die von den Fürsten beispielhaft vorgelebte und also auch für die Untertanen verbindliche Norm. Ihr paßt sich deshalb der jüdische Karrierist Jadassohn, den die Namensänderung von Judassohn in Jadassohn weiterhin und erst recht als Juden erkannt und verachtet sein läßt, mit besonderem Eifer an. Ja, er läßt den Antisemitismus überhaupt erst virulent werden, wo er zuvor bloße Rhetorik gewesen und als solche bereits zu nichts verpufft war.

Das schließlich gegen Lauer $^{7}$ verhängte Urteil wegen Majestätsbeleidigung zu sechs Monaten Gefängnis ist offensichtlich ungerecht. Trotzdem wirkt in ihm der Antisemitismus nicht nur aus der Perspektive des Holocaust, in den er mündete, vom Autor verharmlost. Opfer des Antisemitismus im Roman ist, im Unterschied zu Schnitzlers Professor Bernhardi, nicht etwa ein Jude, sondern der Nichtjude Lauer. Der Jude Jadassohn dagegen ist neben Heßling der große Gewinnler des Prozesses. ${ }^{8}$ Sein Antisemitismus erinnert an das Witzwort, das Egon

${ }^{7}$ Der Nichtjude Lauer ist trotz seiner allgemeinen Menschenfreundlichkeit selbst Antisemit, wenngleich ein gemäßigter, da er nach seiner Bemerkung über die "verjudeten Fürstenhäuser" Wert auf die Feststellung legt, er wolle damit nichts gegen seinen jüdischen Freund, den Kaufhausbesitzer Cohn, gesagt haben.

${ }^{8}$ Auch in Schnitzlers Komödie gibt es einen Juden, dem "der Part des überangepassten Konvertiten zugedacht [ist]." (Rolf-Peter Janz: "Professor Bernhardi - 'eine Art medizinischer Dreyfus'? Die Darstellung des Antisemitismus bei Arthur Schnitzler" in: Akten des Internationalen Symposiums 'Arthur Schnitzler und seine Zeit', hrsg. Giuseppe Farese, Bern 1985, 
Schwarz zum Beleg der Entstehung von jüdischem Selbsthaß aus Schnitzlers autobiographischem Bericht Jugend in Wien (geschrieben 1915-1920, erstmals veröffentlicht 1968) zitiert: Es sei "der Antisemitismus [...] erst dann zu Ansehen und Erfolg gediehen, als die Juden sich seiner angenommen." ${ }^{9}$ Fraglos war es die Intention von Heinrich Manns Satire, dem Leser den von Jadassohn ertrotzten Vorteil von vornherein desto gewisser als selbstzerstörerisch hinzustellen, je weniger Jadassohn die eigene Schuld selbst zu sehen vermag.

Doch wollte Heinrich Mann in seinem Roman die Eigenschaft selbstzerstörerischen Egoismus nicht als spezifisch jüdisches Problem vorführen, sondern als das Problem des deutschen Kaiserreichs überhaupt. Jadassohn blieb Nebenfigur; der Autor, dem marxistischen Kampf gegen die ausbeutenden Klassen verpflichtet, wählte zur Haupt- und Paradefigur des deutschen Kaiserreichs den Fabrikbesitzer Heßling. Von dem aber gibt es genauso wenig wie von Jadassohn - oder irgend einer Figur in Schnitzlers Professor Bernhardi - eine Brücke zu dem massenmörderischenen Añtisemitismus der Nazihenker. Es ist zwar richtig, daß Heßling in seiner Auseinandersetzung mit dem Maschinenmeister Napoleon Fischer rassistisch reagiert: "Ein animalischer $\mathrm{Ha} ß$ stieg in Diederich herauf, der Haß seines blonden Fleisches gegen den mageren Schwarzen, den Menschen von einer anderen Rasse, die er gern für niedriger gehalten hätte und die ihm unheimlich schien." (83-84) Doch wirkt solcher Rassismus sogleich wieder relativiert, wenn Heßling schon auf der nächsten Seite

S. 113.) Doch gibt es da wichtige Unterschiede. Der jüdische Dozent Schreimann trägt zum stolzen Beweis seines Deutschtums aus der Zeit seiner Mitgliedschaft in einer schlagenden Verbindung einen SchmiB. Da er seine bisherige Karriere jenem Professor Ebenwald verdankt, der sich selbst einen "Führer der Deutschnationalen strengster Observanz" nennt (Professor Bernhardi und andere Dramen [Das dramatische Werk, Bd 6], Frankfurt a.M. 1981, S. 185), unterstützt er ihn lautstark in dessen Kampf gegen Bernhardi. Seine äußere Aggressivität bleibt dabei aber immer als künstliche durchschaubar, da er mit seinen Angriffen gegen Bernhardi dem Professor Ebenwald nur sekundiert, wo Jadassohn im Prozeß gegen Lauer Heßling in die Attacke zwingt. Während der Nichtjude Professor Ebenwald in seiner neuen Funktion als Direktor des Elisabethinums die Nachfolge Bernhardis antritt und so wie Jadassohn einen Karrieresprung schafft, erreicht Schreimann für sich selbst nicht mehr als die Absicherung des bereits Erreichten.

${ }^{9}$ Egon Schwarz: "Arthur Schnitzler und das Judentum" in: Im Zeichen Hi$o b s$, hrsg. Hans-Peter Bayerdörfer, Königstein 1985, S. 69. 
einen Arbeiter und eine Arbeiterin, die er des Mißbrauchs der Arbeitszeit für ein privates Schäferstündchen verdächtigt, undeutschen Verhaltens beschuldigt und aus seiner Fabrik entläßt. Es ist derselbe Arbeiter, der dann später von dem Wachtmeister erschossen und so zum indirekten Anlaß für den Prozeß gegen Lauer wegen Majestätsbeleidigung wird. Niemand käme auf den Gedanken, diesen Arbeiter zum Opfer von Heßlings Antisemitismus zu erklären. Vielmehr ist er eindeutig nur das Opfer von Heßlings Besorgnis, der mangelnde Einsatz seiner Arbeiter könne seinen Profit beeinträchtigen.

Insbesondere kann man nicht auch nur entfernt in Heßling schon einen Vorläufer Hitlers sehen. Zwar kann Heßling durch sein "Blitzen" seine Arbeiter zum Schweigen bringen ("das Getuschel der Frauen verstummte unter dem Blick des Herrn" (84)) und sie auf diese Weise in Schach halten. Es gelingt ihm aber nirgends - und es ist auch gar nicht seine Absicht -, die Arbeiter oder gar die Massen wirklich auf seine Seite zu ziehen und ihnen so seine Untertanenideologie einzupflanzen. Im übrigen sind seine rassistischen Äußerungen, die sich gegen Napoleon Fischer richten, nicht für seine Arbeiter oder gar für die Massen bestimmt. ${ }^{10}$

Näher an der nationalsozialistischen Zukunft als Heinrich Mann und Arthur Schnitzler war schon vor dem Ersten Weltkrieg ein anderer Wiener aus der Umgebung Schnitzlers: der Journalist, Theaterkritiker, Dramatiker und Romanautor Felix Salten.

II.

Felix Salten, d.i. Siegmund Salzmann (1869-1947), war schon kurz nach der Jahrhundertwende, statt wie Hofmannsthal erst seit Beginn des Ersten Weltkriegs, ein politisch engagierter Schriftsteller und als solcher über den Status des unpolitischen Ästheten ${ }^{11}$ hinaus. Freilich nicht in seinen

${ }^{10} \mathrm{Zum}$ alten Buchhaiter, aber doch eher beiseite und zur eigenen Erbauung gemeint: "Sehen Sie mal, Sötbier, die Vorderflossen hängen ihm bis an den Boden. Gleich wird er auf allen vieren laufen und Nüsse fressen." (86).

11 "Unpolitisches Ästhetentum" ist das Ideal, das der Literaturhistoriker Zmegac (Geschichte der deutschen Literatur, II (1848-1918), Königstein 1980, S. 261) im Blick auf das Wien der Jahrhundertwende "den angehenden Künstlern und Akademikern aus den Kreisen des wohlhabenden Bürgertums" insgesamt ankreidet. 
literarischen Werken, sondern als Essayist und Zeitungsjournalist. ${ }^{12}$ Seine Verbindungen zur Presse und seine Theaterrezensionen spielten bereits eine nicht unwichtige Rolle bei der Verbreitung der Ideen des Jungen Wien, ${ }^{13}$ und sein Kritikerberuf brachte in seiner Beziehung zu den Künstlerfreunden eine eigene Problematik mit sich. ${ }^{14}$ Es war offenbar seine Rolle als Journalist, die die Freundschaft mit den Wiener Dichterkollegen Schnitzler, Hofmannsthal und Beer-Hofmann immer wieder auf die Probe stellte. Offensichtlich war für Salten, der im Unterschied zu ihnen aus einer erst in der Generation des Vaters nach Wien gekommenen und finanziell und sozial ungesicherten jüdischen Familie stammte, ${ }^{15}$ die tendenziell schizophrene Zweiteilung seiner Rolle als Künstler und als politisch engagierter Journalist im persönlichen Umgang mit den Freunden nicht leicht durchzuhalten.

Eine ähnliche Geringschätzung für seine Rolle als Journalist scheint er

${ }^{12}$ Zum sechzigsten Geburtstag ehrt Hofmannsthal Salten, dem er in seinen Briefen immer nur eine untergeordnete Rolle zubilligt, mit einem Text, in dem er ihn als Künstler, Kritiker und Politiker würdigen möchte. In allen drei Punkten tut er es mit Einschränkungen, am wenigsten aber doch beim dritten: "Politiker - ja und nein. Keine der Bindungen, keine der Starrheiten, welche diese Situation mit sich bringt. Und immer wieder doch, immer aufs neue Politiker, aus Temperament, aus Kampflust, aus Wille zur Entscheidung." (Gesammelte Werke in Einzelausgaben, Prosa IV, Frankfurt a.M., S. 518).

${ }^{13}$ Lore Muerdel Dormer: "Felix Salten" in: Major Figures of Turn-of-theCentury Austrian Literature, edited and with an Introduction by Donald G. Daviau, Riverside 1991, S. 408.

${ }^{14}$ In Hofmannsthals bereits zitierter Würdigung zu Saltens sechzigsten Geburtstag ist zwischen den Zeilen nur allzu deutlich zu lesen, daß nach Hofmannsthals Urteil der Journalist Salten dem Künstler Salten im Wege steht: "Künstler - durchaus, und aus der Wurzel, und leidenschaftlich. Aber selbst an diesen Novellen, an denen das Künstlerische, das konsequent Dichterische sehr stark ist, ein anderes ist stärker: die Spontaneität."Gleichfalls anläßlich von Saltens sechzigsten Geburtstag klagt BeerHofmann in einem Brief vom 28. VIII. 1929 an Schnitzler: "Er [sc. Salten] ist mistrauisch, grundsätzlich leicht verletzt, immer witternd, man schätze ihn nicht genug, dabei - in seiner Eigenschaft als Kritiker - zu leicht der Ansicht zugeneigt, man tue etwas um ihn bei guter Laune zu erhalten - sogar 'bei uns [...]" Beer-Hofmann ist deshalb nicht bereit, Salten zum Geburtstag 'Blumen zu schicken, sondern höchstens ein Telegramm. (Arthur Schnitzler, Richard Beer-Hofmann: Briefwechsel, 1891-1931, hrsg. Konstanze Fliedl, Wien 1992, S. 232).

${ }^{15}$ Einzelheiten zu Saltens Herkunft bei Kurt Riedmüller: Felix Salten als Mensch, Dichter und Kritiker, Diss., Wien 1949, S. $6 \mathrm{ff.}$ 
von den deutschen Schriftstellern Thomas und Heinrich Mann nicht erfahren zu haben. Die Brüder Mann waren Zeitungsleser, die sich unter anderem auch für die Wiener Presse interessierten, in der Felix Salten schrieb. Im Oktober 1905 schickte Thomas Mann seinem Bruder einen Ausschnitt aus der Wiener Tageszeitung Die Zeit mit einem Verriß von Edward Stilgebauers Roman Götz Krafft. Die Geschichte einer Jugend. Der Verriß, dessen Witz Thomas Mann so gefiel, daß er ihn Heinrich nicht vorenthalten wollte, stammte von Felix Salten. ${ }^{16}$ Heinrich Manns Antwort ist nicht bekannt, so daß wir nicht wissen können, wie er auf den Zeitungsausschnitt reagierte. Doch konnte Thomas Mann bei seinem Bruder die Kenntnis des Namens Salten voraussetzen. Heinrich hatte in einem Brief an den Freund Ludwig Ewers schon ein Jahr zuvor Saltens Stil in der Zeit als "amüsant und doch mit Würde" gerühmt und Salten seinen "literarischen Freund" genannt. ${ }^{17}$ Unklar ist nur, ob und wann er mit dem zwei Jahre älteren Salten auch direkte persönliche Beziehungen angeknüpft hat. Er könnte ihm natürlich wie sein Bruder Thomas im Hause Schnitzler begegnet sein. Als Salten 1906, also im Jahr nach jenem Verriß von Stilgebauers Roman, Feuilletonredakteur der 'Berliner Morgenpost' wurde, lag Heinrich Manns Berliner Zeit als Volontär bei S. Fischer (1890-92) schon lange zurück.

1906 ist aber das Jahr, in dem er nach eigener Aussage (in Ein Zeitalter wird besichtigt) an seinem "Roman des bürgerlichen Deutschen unter der Regierung Wilhelms II." zu arbeiten begann, dessen erster Band dann Der Untertan wurde. Noch im selben Jahr 1906 wollte er, wie wir aus einem Brief an seinen Freund Ewers wissen, Salten in Berlin besuchen. Das stellte sich dann als unmöglich heraus, da Salten mittlerweile schon wieder nach Wien zurückgekehrt war, weil er es in Berlin nicht ausgehalten hatte. ${ }^{18}$ Der nicht zustande gekommene Besuch ist von Interesse,

${ }^{16}$ Brief von Thomas an Heinrich Mann vom 15. 10. 1905. (Thomas Mann, Heinrich Mann: Briefwechsel 1900-1949, hrsg. Hans Wysling, Frankfurt a.M. 1984, S. 59).

${ }^{17}$ Heinrich Mann: Briefe an Ludwig Ewers 1889-1913, Berlin 1980, S. 405. - Am 23. 12. 1905 berichtet Heinrich Mann Ewers, daß Salten in der Zeit alles billige, was er, Heinrich, mache, und daß er hoffe, Salten werde einen Vorabdruck seiner Novelle Schauspielerin in der Zeit durchsetzen. (S. 410411).

${ }^{18}$ Brief an Ewers vom 31. 10. 1906. (S. 423). 
weil Heinrich Mann da mit Salten wahrscheinlich nicht nur, wie im bereits zitierten Brief erwähnt, über Ewers sprechen wollte, sondern auch schon über den dort gleichfalls erwähnten Plan, einen "Byzantiner, der eine Papierfabrik haben soll", zum Helden eines eigenen neuen Romans zu machen.

Wann immer die Beziehung zwischen Heinrich Mann und Salten begonnen hat: Sie erwies sich als künstlerisch fruchtbar für beide Seiten. Schon Thomas Manns Hinweis auf Saltens Stilgebauer-Rezension scheint Folgen für den Untertan gehabt zu haben. Man kann Heinrich Manns Roman lesen, als wäre er direkt gegen Stilgebauers Götz Krafft angeschrieben. Salten hatte seinem Verriß den Titel "Gottes Segen bei Bong" gegeben. Das war eine Anspielung darauf, daß das Pfarrerkind Götz Krafft, der Titelheld des im Verlag Bong erschienenen Romans, mit den Predigten des Vaters von der Bedeutung der bestehenden Staatsform, "von Gott, König und Vaterland!"19 zunächst nichts anfangen kann und deshalb nur aus ökonomischen Gründen Theologie studieren will, am Ende aber, indem er von der Theologie zur Literaturwissenschaft wechselt, doch noch seinen Frieden mit Gott macht. Von hier aus erklärt sich die oben als überraschend bezeichnete Wendung im Untertan, daß auch Heßling am Ende des Romans die Notwendigkeit eines Arrangements mit Gott sieht. Selbst bei nur flüchtigem Nachlesen in Götz Krafft ist leicht zu sehen, daß Heinrich Mann auch an anderen Stellen für Diederich Heßlings Charakter nicht wenig vom Helden dieses Romans geborgt hat, dabei nur sorgfältig darauf achtend, daß Götz Kraffts positive Neigung zum Liberalismus Diederich Heßling fremd bleibt und ihm nur in Gestalt des alten Buck, jenes aufrechten Achtundvierzigers, gegenübertritt. Buck, der alte Liberale, steht im Roman für die liberalen Prinzipien, die Götz Krafft durchgehend hochhält. Wie der alte Buck - im dritten Kapitel des Untertans - ist schon Götz Krafft ein Bewunderer von Herwegh, wie Buck zitiert er Herweghs "Lieder eines Lebendigen" (27) und wird er wegen seiner Bewunderung für die Achtundvierziger - "Du, die Achtundvierziger, das sind doch dolle Kerls gewesen, wenn man die so liest, da geb' ich den ganzen Rummel von anno 70 für hin, da war noch Idealismus drin, zumdonnerwetter!" (ebd.) - als "Republikaner" eines zweifelhaften Verhältnisses zur Monarchie verdächtigt. (40) Dagegen er-

${ }^{19}$ Edward Stilgebauer: Götz Krafft. Die Geschichte einer Jugend, I, Berlin 1904, S. 54. 
scheint bei Diederich Heßling jeweils in satirischer Verzerrung, was bei Götz Krafft positiv gemeint ist: angefangen damit, daß Götz Krafft "eine hohe, blondhaarige Erscheinung, ein offener Kerl mit blitzenden, blauen Augen" ist (15), über seinen $\mathrm{Haß}$ auf den "soldatischen Zwang" (39), seine "im Grunde ihres Wesens weiche Seele, der nur sein eiserner bis zu starrem Eigensinn entwickelter Wille die Wagschale hielt" (79), seine Vorliebe für Süßigkeiten, seine romantische Liebe zu Garten und Elternhaus' als einer Märchenidylle und zu den Büchern (83), seine kindliche Furcht vor den glühenden Augen zwar nicht einer Kröte, wohl aber einer Katze in einer dunklen Ecke (103), bis hin zu seinem Kampf mit der Autorität des Vaters und der Autorität Gottes.

In Saltens 1910 veröffentlichter Erzählung Olga Frohgemuth dürfen wir eine charmante Wiener Variante von Heinrich Manns 1905 erschienenem Roman Professor Unrath sehen. Olga Frohgemuth, Pendant der Künstlerin Fröhlich aus Heinrich Manns Professor Unrat, verstört bei Salten mit Ihrem Lebenswandel einen Gymnasialprofessor nicht als dessen Geliebte, sondern als dessen Tochter, indem sie ihr bürgerliches Dasein zugunsten einer öffentlichen Karriere als Sängerin aufgibt und sich in dieser Stellung mit einem kaiserlichen Prinzen einläßt. Natürlich war die Verführung des Bürgers durch das Kaisèrtum dann auch das Thema, das Heinrich Manns Untertan kennzeichnet, der 1914 zwei Monate vor Ausbruch des Ersten Weltkriegs beendet und kriegsbedingt erst 1918 veröffentlicht wurde. Allerdings soll damit keine Abhängigkeit konstruiert werden. Salten hatte nämlich mit seiner Erzählung sowenig politische Ziele verfolgt wie Heinrich Mann zuvor mit Professor Unrath. Heinrich Mann konnte also für seinen "Byzantiner" in der Erzählung Olga Frohgemuth keinerlei Vorbild finden. Desto mehr aber in Saltens Lueger-Essay, auf den deshalb hier - zusammen mit seinem schon früher veröffentlichten Essay über Wilhelm II. - genauer einzugehen ist.

Salten veröffentlichte den Lueger-Essay im Jahre 1909, also im Jahr vor der Veröffentlichung von Olga Frohgemuth, in seinem Band Das österreichische Antlitz. Der Essay gibt sich als Vorschlag zu einem LuegerRoman, in dem Saltens Skizze in ein vollendetes Werk umgesetzt werden sollte. Der erste Satz des Essays lautet: "Vielleicht kommt es auch dazu, und es greift einmal jemand nach diesem Mann und stellt ihn mitten in einen Wiener Roman, und rollt sein Leben auf und enthüllt sein Schick- 
sal." 20

Bei der Titelfigur des zu schreibenden Romans handelte es sich um den damaligen Wiener Bürgermeister Dr. Karl Lueger. Salten bot bei der Zeichnung dieser bekannten österreichischen Figur, im Unterschied zu der Gesellschaftskritik in seiner Erzählung Olga Frohgemuth, direkte und aggressive politische Satire. Sie sollte unmißverständlich klar machen, welche Gefahr er für Österreich von einem Staatsbürger ausgehen sah, der unter der Maske des Biedermannes die Autorität des österreichischen Kaisers herauszufordern und für sich selbst zu usurpieren versuchte. Es galt, den Biedermann durch entlarvenden Nahblick zu demaskieren. Und der fiel insebesondere auf Dr. Luegers Barttracht. Bei genauerem Hinsehen nämlich, so Salten, "zeigt sich, vom soliden, wackeren Bart verborgen, ein spöttischer Mund, der hinter der Ehrlichkeit grauer Haare schadenfroh zu lächeln vermag." (131) Für Lueger und seine Gefolgschaft hat seine Barttracht, statt nur ein heimliches Laster zu verhüllen, eine direkte und offene Signalwirkung. Sein "außerordentlich solider Vollbart, der am Kinn nach dem Geschmack der Vororte geteilt ist" (ebd.), verkörpert unter dem Fanal der Solidität gerade umgekehrt ein revolutionäres Programm, das auf Überwindung dessen aus ist, was in Österreich unter dem Regime des Kaisers bis dato als solide gegolten hatte. Die Signalwirkung des Bartes ergibt sich also, noch ehe der Nahblick auf den spöttischen Mund fällt, aus der Abweichung von der Barttracht des Kaisers. Das ist umso bedeutsamer, als Dr. Lueger sonst in allem "mit einer vollkommen monarchischen Technik [arbeitet]." (138) Da also zum Beispiel sein Bild in "den Amtslokalen, in den Schulzimmern, in den Wirtshäusern, in den Theaterfoyers, in den Schaufenstern" allgegenwärtig ist (ebd.), signalisiert sein Vollbart jedesmal neu die Stärke und Unabhängigkeit des Bürgermeisters vom Kaiser. Der nämlich trägt keinen Vollbart, sondern einen schütteren Backenbart. Dabei schildert Salten den Bürgermeister als einen Mann, der prinzipienlos von den Liberalen zu den Demokraten und von diesen wiederum zu den Deutschnationalen des militant rassistischen Antisemiten Schönerer übergewechselt war und bei der Begründung der christlich-sozialen Partei für sich die "breite Masse der Kleinbürger" ent-

${ }^{20}$ Das österreichische Antliz, Berlin [1909], S. 127-142, hier S. 129. (In Auszügen abgedruckt in Die Wiener Monderne. Literatur, Kunst und Musik zwischen 1890 und 1910, hrsg. Gotthart Wunberg, Stuttgart 1981, S. 124131). 
deckt hatte, die "führerlos blökend wie eine verwaiste Herde durch die Versammlungslokale [irrte]." (132) Indem er sich ihnen als Führer anbot, war er in ein Konkurrenzverhältnis zum Kaiser geraten, das ihn alsbald gegenüber dem Kaiser in Vorteil brachte und ihm so zu jener heimlichen Schadenfreude verhalf, die der Vollbart bei genauerem Hinsehen nicht verhüllen kann. Salten beschreibt, um dies zu demonstrieren, Luegers Auftritt bei einer Fronleichnamsprozession: "Jetzt geht er in der Fronleichnamsprozession vor dem Baldachin einher. Die Glocken läuten, die Kirchenfahnen wehen, und das brausende Rufen der Menge empfängt den geliebten Mann [sc. Lueger], der nach allen Seiten dankt, grüßt, lächelt. Er freut sich. Denn der Kaiser, der dem Baldachin folgt, muß den tausendstimmigen Donner hören. Auf dem ganzen Weg rauscht dieser Jubelschrei vor dem Kaiser einher, dieses jauchzende Brüllen, das einem anderen gilt." (135)

Da die politischen Verhältnisse in Deutschland anders lagen, hat Heinrich Mann Saltens Verfahren nur formal übernommen und im Untertan die Zielrichtung des Entlarvungsprozesses umgedreht. Statt in heimlicher Abweichung von der Linie des Kaisers und im Aufbegehren gegen ihn lag die Gefahr in Deutschland, so wie Heinrich Mann sie sah, in der bis zum sklavischen Kopieren getriebenen Loyalität des Untertans gegenüber einem Kaiser, dessen Charakter das ursprüngliche, von den kaisertreuen Kopierern nur mehr vervielfältigte Problem darstellte. Wieder freilich war es Salten, der im Jahre 1905 - also im selben Jahr, in dem Thomas Mann an Heinrich den Zeit-Ausschnitt mit Saltens Verriß von Stilgebauers Roman Götz Krafft schickte - bereits ein einschlägiges Porträt Wilhelms II. entworfen hatte. Gleich der erste Essay in Saltens bei Georg Müller in München und Leipzig verlegtem Buch der Könige, einem schmalen Bändchen mit Essays über die gekrönten Häupter der Zeit, ist dem deutschen Kaiser gewidmet. Schon in den einleitenden Sätzen findet sich dort die uns aus Heinrich Manns ein Jahr später begonnenem Roman vertraute These von der identitätsstiftenden, wechselseitigen Abhängigkeit von Kaiser und Untertan:

Seinem [sc. Wilhelms II.] erhabenen Beispiel ist es zu danken, wenn jetzt beinahe alle deutschen Männer, die sich's überhaupt leisten können, diesen hochfahrenden, jähen und drohenden 
Schnurrbart tragen. Solch ein Schnurrbart ist einfach ein Programm, eine sichtbar gewordene, emporgezwirbelte Gesinnung. Man kennt den Untertan, wenn man seinen Schnurrbart kennt. ${ }^{21}$

Wilhelm II. ist, daran läßt Salten keinen Zweifel, eine problematische Figur. Wie später in seinem Lueger-Essay in bezug auf den Wiener Bürgermeister, erklärt er auch hier, es müsse sich einmal jemand des deutschen Kaisers annehmen und "die ganze Angelegenheit ins Reine bringen." (6) Es müßte das "natürlich einer sein, der es vermag, auch gekrönte Menschen zu wägen und zu werten, einer, an dessen Urteil alle glauben, und er müsste uns endlich genau sagen, ob der deutsche Kaiser ein grosszügiger oder nur ein beweglicher Mensch sei ..." (Ebd.) Gleichfalls wie im Falle des Wiener Bürgermeisters, mit dem Wilhelm II. den Drang zu schauspielerischer Selbstinzenierung teilt, liefert Salten auch beim deutschen Kaiser dann doch schon selbst die entscheidenden Stichworte für die zu erstellende Diagnose - angefangen bei des Kaisers theatralisch geschauspielertem soldatischen Schneid bis hin zu seiner Jupiterattitüde des "Blitzens":

[...] ein Soldatengesicht von jenem Heroismus des Ausdrucks, der Frisur und Haltung, den Schönthan und Gustav v. Moser auf die deutsche Bühne bringen. Ein Gesicht, in dem Tüchtigkeit und ein strammer Wille geschrieben stehen ..., das zu einer majestätischen Herrschermiene sich zwingt ... Der Kaiser zieht die Brauen hoch, wenn er jemanden anspricht, reisst die Augen auf, 'blitzt die Menschen an', wie man wohl sagen soll. (7)

Hinter der Attitüde entdeckt Salten die tiefsitzende Unsicherheit. ("Er hat nicht die Art der Könige, die sich beobachtet fühlen, sondern viel eher die Art der Menschen, die sich unablässig selbst beobachten, die ihre eigene Wirkung auf andere ständig kontrollieren." [Ebd.]) Die Unsicherheit aber beruht darauf, daß der Kaiser sich selbst als Untertan versteht, zwar nicht gegenüber einer anderen kaiserlichen Person, wohl aber gegenüber dem durch Erbschaft auf ihn gekommenen Leitbild des deutschen Kaisers, von dem er glaubt, daß es perfekt sein müsse in jeder nur denkbaren Beziehung

${ }^{21}$ Das Buch der Könige, mit Zeichnungen von Leo Kober, München und Leipzig [1905], S. 5-8, hier S. 5. 
- und daß er selbst es perfekt ausfüllen müsse:

Denn Wilhelm II. ist auch ein bewundernder und er ist ein dankbarer, dazu noch ein fleissiger Erbe. Er ist der glühendste Verehrer des deutschen Kaisers ... Vielleicht rührt auch sein Streben nach Vielseitigkeit, sein Ehrgeiz, sich in allen Künsten und Wissenschaften zu betätigen, nur daher, dass er glaubt, der deutsche Kaiser müsse schier ein Ausbund von Genialität und universaler Begabung sein. (Ebd.)

Die Passion, mit der Wilhelm II. das Regieren betrieb, ließ sich nach Salten am besten bei drei regelmäßig wiederkehrenden Auftritten beobachten: "wie er in Potsdam sein Regiment zur Kaserne führt, wie er in Berlin durch den Tiergarten reitet, wie er auf dem Subskriptionsball den Saal betritt." (7/8) Der zweite Schauplatz spielt eine wichtige Rolle im Untertan: am Ende des ersten Kapitels in der Begegnung zwischen Heßling und dem Kaiser. Es ist der Tag gefährlicher politischer Unruhen, die über Berlin kommen wie ein drohend grollendes Gewitter, ${ }^{22}$ als der Kaiser auf dem Weg vom Schloß zum Tiergarten zunächst am Brandenburger Tor, dem damaligen Siegestor, den in den Massen verborgenen Heßling ebenso heroisch übersieht wie all die anderen. Im Tiergarten, in den ihm Heßling mit größter Anstrengung vorausgeeilt ist, glaubt er dann plötzlich in dem verdächtig Einzelnen einen fanatisierten Sozialisten vor sich zu haben. Aber nur, um laut aufzulachen und sich vor Vergnügen auf den Schenkel zu schlagen, als er in dem scheinbar so gefährlichen Heßling zu seiner Erleichterung einen Kaisertreuen, einen treuen Untertan entdeckt, der sich im Angesicht des Kaisers vor ehrerbietigem Schrecken in einen Tümpel gesetzt hat.

Heinrich Mann war sich aber schon bei dem geplanten Besuch Saltens im Jahre 1906 sicher, daß sein Roman nur am Rande in der Hauptstadt Berlin, vorrangig jedoch in der deutschen Provinz spielen sollte. ${ }^{23} \mathrm{Im}$

22 "Ein deutlicheres Grollen, ausbrechend aus der Tiefe, jetzt drüben, jetzt hier: 'Brot! Arbeit!' Anschwellend über die Menge hinrollend, wie aus einer Gewitterwolke [...]" (S. 44) Aus diesem Erlebnis Heßlings im ersten Kapitel erklärt sich dann im letzten Kapitel seine Angst, das plötzlich hereinbrechende unbildlich-wirkliche Gewitter bedeute das Ende des Kaiserreichs.

${ }^{23}$ Brief an Ewers vom 31. 10. 1906. 
Unterschied zu Saltens Bürgermeister Lueger hatte Diederich Heßling fern von der Hauptstadt in einem Provinznest zu agieren, um damit unmißverständlich zu demonstrieren, daß es für den wahrhaft kaisertreuen Untertan, um seinen Kaiser im eigenen Phänotyp bis in die Barttracht und das Blitzen seiner Augen hinein zu verkörpern und zu vergegenwärtigen, nicht einmal mehr der physischen Nähe bedurfte. Das "Blitzen", mit dem Heßling seinen Kaiser nachzuahmen versucht, ist Beleg für das besondere Verhältnis des deutschen Untertans zu seinem Herrscher. Es ist entlarvend, weil es Heßlings Ausbeuterrolle nicht mit innerer Autorität erfüllt, sondern nur theatralisch überhöht - genauso, wie dem Kaiser die Pose des blitzeschleudernden Jupiter nur als Mittel theatralischer Überhöhung seiner Herrscherrolle dient. Bei beiden belegt die Attitüde das Substanzlose der schauspielerischen Selbstdarstellung. Dem gegenüber sieht Salten - im letzten, titelgebenden Essay der Sammlung Das österreichische Antlitz - in der Angewohnheit der Österreicher, ihren Kaiser Franz Josef nachzuahmen, die Fähigkeit zu echter Repräsentanz, und zwar im direkten Gegensatz zu dem Nachahmungstrieb, den er in Deutschland beobachtet. Denn während er Wilhelm II. abspricht, in seinem Phänotyp überhaupt etwas spezifisch Deutsches zu repräsentieren ("Wilhelm II. würde man, ohne ausdrückliches Wissen, eher für einen Engländer ansprechen", S. 270), deutet er "[Franz Josefs] Wesen, diese ganze unauffällige, diskrete, sorglose und ihrer selbst unendlich sichere Eleganz" als originär österreichisch: "Nachahmung allein kann das nicht zuwege bringen. Auch greift Nachahmung allein nicht so weit um sich, dringt nicht so ins Breite und Tiefe, sickert nicht so unaufhaltsam durch alle Schichten der Stände. Wenn sie den Kaiser nur nachahmen würden, wäre dies alles gezwungener und leichter kenntlich." (273) Saltens Porträt des österreichischen Kaisers liest sich überhaupt wie das positive Gegenbild zu dem bramarbasierenden Charakter des deutschen Kaisers: "Österreichisch ist sein [sc. Franz Josefs] Hang zum Unauffälligen, sein kultivierter Geschmack, der allem Gellenden, allem Schmetternden, allem Unterstrichenen und überlaut Betonten abhold ist. Österreichisch, wie seine Haltung, die nicht bolzengerade, nicht 'stramm' mit aufgeworfenem Kopf soldatischen Geist zu markieren strebt, ist seine Diskretion, die vor allem Theatralischen, vor allem Exaltierten als vor etwas Unmöglichem scheu zurückweicht." (274) 
Den Bürgermeister Lueger dagegen sieht Salten ausdrücklich, wie zuvor im Buch der Könige den deutschen Kaiser, als theatralischen Charakter: "Wichtig ist, auch für den Roman, sein Äußeres: eine glänzende Bühnenerscheinung; die beste, die es für das Rollenfach des Demagogen gibt." (Das österreichische Antlitz, S.130) Und doch ist Heßlings Schauspielerei anderer, eben "deutscher" Art, sofern hinter seinen Aktionen im Unterschied zu Lueger kein heimlicher Wettbewerb mit dem Kaiser verborgen ist. Zwar maßt sich auch Heßling geradezu selbst die Kaiserrolle an, als er ein selbst verfaßtes Telegramm, das die Ermordung von streikenden Arbeitern durch Soldaten zur Heldentat erklärt, mit dem Namen des Kaisers unterzeichnet. Er stellt sich da aber mit dem Kaiser, indem er sich mit ihm identifiziert, nur gleich, nicht über ihn wie Lueger, der seinen Kaiser verdrängen will. Folgerichtig hat Wilhelm II. auch keinerlei Grund, sich seinerseits von diesem Untertan, der sein Denken nur vorwegnimmt, zu distanzieren. In der Wirklichkeit wie in Saltens Lueger-Essay verweigert Franz Josef dem Dr. Lueger nach seiner Wahl zum Bürgermeister dreimal die Bestätigung, weil er von seinem Antisemitismus abgestoßen ist. Bei Heinrich Mann dagegen bestätigt Wilhelm II. mit einem höchstselbst verfaßten Telegramm, natürlich ohne es zu wissen, das von Heßling in seinem Namen gegebene Kaiserwort der Belobigung des Wachtmanns für die Erschießung des Arbeiters.

Als wichtigste Übereinstimmung zwischen dem deutschen Untertan Dr. Diederich Heßling (und seinem Kaiser) einerseits und Saltens Dr. Karl Lueger andererseits ergibt sich jedoch - neben dem Hang zum Theatralischen - ein ungehemmter Ehrgeiz, der unter dem Vorwand des allgemeinen Fortschritts unverhohlen vor allem den eigenen Vorteil betreibt: "Überall lehnte man ihn [sc. Dr. Lueger] ab, von seinem stürmischen Ehrgeiz beunruhigt. Überall auch spürte sein Instinkt: diese Mühlen klappern zu wenig, mahlen zu langsam." (130) Im Untertan ist der Held Besitzer einer Papiermühle, die er von seinem Vater übernommen hat, und nicht nur diese Mühle, sondern alle Institutionen des Landes, mit denen er es zu tun bekommt, klappern ihm zu langsam. ${ }^{24}$ Der Dr. Lueger des Essays war, solange es den eigenen Zwecken diente, durchaus bereit, jederzeit die totale Umkehrung seiner Prinzipien in Kauf

${ }^{24} \mathrm{Zu}$ seiner Auseinandersetzung mit Sötbier, Napoleon Fischer und den Arbeitern über den angeblichen administrativen und technischen Rückschritt seiner Fabrik vgl. wiederum das 3. Kapitel des Untertans. 
zu nehmen, weil sein persönlicher Ehrgeiz Prinzipien in Wahrheit nicht zuließ: "[Karl Lueger] hat sich vielen Parteien angeboten. Er begann als der Schüler eines jüdischen Oppositionskünstlers im Gemeinderat, ging zu den Liberalen, zu den Demokraten; und pries zu Schönerers Füßen die teutonische Heilslehre." (Ebd.) Luegers Verrat an den Liberalen erinnert also bereits an das Verfahren, mit dem Heßling sich zunächst gegenüber dem Liberalen Buck als "selbstverständlich durchaus liberal" einzuschmeicheln versucht, um diese Verbindung dann alsbald zugunsten der ihm profitabler erscheinenden mit den Konservativen aufzugeben. Daß Lueger bei jeder neuen Wendung gleichwohl Prinzipien zu haben behauptet, ist die ihn immer wieder neu definierende Lüge; sie macht seinen Namen zu einem sprechenden, wenn man ihn nicht in der in Wien üblichen dreisilbigen Aussprache (Lu-eger), sondern zweisilbig als Lüger liest. (Schon der Essaytitel mit dem nackten Wort "Lueger", das ohne Doktortitel und Vornamen nicht als Name des Bürgermeisters erkennbar war, lud zu solcher Lesart ein. $)^{25}$ Entsprechend hat Heinrich Mann seinem Lueger den Namen Heßling gegeben, und durch die Schreibweise Heßling statt Häßling oder gar Häßlich wird das Sprechende des Namens dieses Romanhelden, ähnlich wie bei dem historischen Lueger, durch den Blick auf den Charakter deutlich. Sein Vorname Diederich drückt, als Dietrich gelesen, zugleich die von Salten für den Helden geforderte Schlüsselrolle aus, die er im Roman für die Entlarvung eines ganzen Volkes spielen soll: Zu Beginn von Saltens Essay, gleich nach der Forderung, daß einmal jemand Lueger "mitten in einen Wiener Roman" stellen möge, heißt es: "Wie man einen Schlüssel ins Schloß fügt, so müßte derjenige, der es unternimmt, diesen Roman zu schreiben, den Lueger-Charakter in das Herz des. Wiener Volkes einfügen und dieses Herz damit aufsperren, daß alle seine Kammern offen stünden." (129) Heinrich Mann hat hier in dem Vornamen, entsprechend dem häßlichen Charakter seines Helden, zusätzlich die kriminelle Gewaltsamkeit ausgedrückt, mit

${ }^{25}$ Den genauen Blick, der die Verstellung aufdeckt, braucht Salten freilich nicht in bezug auf den Namen, sondern auf das äußere Erscheinungsbild des Mannes: "In der Nähe erst wird es sichtbar, welch ein unruhig flackernder Schimmer von Schlauheit und Verstellung dies Antlitz überbreitet, das auf Ansichtskarten schön ist." (Das österreichische Antlitz, S. 131) Hinter der äußeren Schönheit, die für sich genommen auf einen biederen Charakter schließen ließe, zeigt sich die innere Häßlichkeit, durch die die äußere Schönheit als Lüge entlarvt wird. 
der Diederich sich selbst nicht nur als Schlüssel, sondern eben als gewaltsamen Dietrich in das Herz des deutschen Volkes "einfügt".

Es ist aber gerade die Präsentation von Heßlings Gewalt, mit der Heinrich Manns Roman des untergehenden deutschen Kaiserreichs dann hinter der visionären Kraft der Zeitanalyse von Saltens Essay zurückbleibt. Der letzte Absatz des Essays lautet: "Dieser Roman wäre zu schreiben. Die Gestalt eines Menschen zu zeichnen, in dem sich der Wille einer Epoche erfüllt hat." (141-142) Salten beschreibt die Ablösung eines liberalen Regimes durch einen die Kleinbürger betörenden Volksverführer, und er legt dabei Wert darauf, daß Luegers Macht nicht auf Gewalt gegen das Volk beruht, sondern auf seiner Fähigkeit, die unzufriedenen Massen auf seine Seite zu ziehen, indem er sie zur Gewalt gegen andere aufstachelt. Lueger verführt die Massen zu neuem Selbstvertrauen, das ihnen aus der Erhebung gegen die moralische Autorität der bestehenden Ordnung zuwachsen soll:

[Lueger] nimmt auch noch die Verzagtheit von den Wienern. Man hat sie bisher gescholten. Er lobt sie. Man hat Respekt von ihnen verlangt. Er entbindet sie jeglichen Repektes. Man hat ihnen gesagt, nur die Gebildeten sollten regieren. Er zeigt, wie schlecht die Gebildeten das Regieren verstehen. Er, ein Gebildeter, ein Doktor, ein Advokat, zerfetzt die Ärzte, zerreißt die Advokaten, beschimpft die Professoren, verspottet die Wissenschaft; er gibt alles preis, was die Menge einschüchtert und beengt, er schleudert es hin, trampelt lachend darauf herum, und die Schuster, die Schneider, die Kutscher, die Gemüsekrämer, die Budiker jauchzen, rasen, glauben das Zeitalter sei angebrochen, das da verheißen ward mit den Worten: selig sind die Armen am Geiste. (132-133)

Die Beschreibung von Luegers wichtigstem Erfolgsrezept geht hier, als Vorwegnahme von Hitlers Wirkungsweise gelesen, an Hellsichtigkeit über die von Heinrich Mann im Untertan gebotene Zeitanalyse hinaus, ja, hinaus auch noch über die Erklärung der Erfolge Hitlers bei den Deutschen, die Heinrich Mann später in Ein Zeitalter wird besichtigt vorgelegt hat. Während Heinrich Mann da auf intellektuelle Denkfaulheit und Verführbarkeit durch vorgetäuschte "Tiefe" abhebt, ${ }^{26}$ beruht der 
Vorzug von Saltens Analyse darauf, daß er den Erfolg von Luegers Rhetorik bei der "breiten Masse der Kleinbürger" nicht nur aus der verkündeten Botschaft, sondern aus der Technik hypnotisierender Massenbetörung ableitet. Man glaubt da, es sei bereits von Hitler statt nur von Lueger die Rede:

Aber wie spricht er auch zu ihnen. Das Dröhnen ihres Beifalls löst erst alle seine Gaben. Beinahe genial ist es, wie er sich da seine Argumente zusammenholt. Gleich einem Manne, der in der Rage nach dem nächsten greift ..., um damit loszudreschen, greift er, um dreinzuschmettern, nach Schlagworten aus vergangenen Zeiten und bläst ihnen mit dem heißen Dampf seines Atems neue Jugend ein, rafft weggeworfenen Gedankenkehricht zusammen, bückt sich nach ... niedergebrochenen Banalitäten, peitscht sie auf, daß sie im Blitzlicht seiner Leidenschaft mit dem alarmierenden Glanz des Niegehörten wirken. In dem rasenden Anlauf, dessen sein Temperament fähig ist, überrennt er Vernunftgründe und Beweise, stampft große Bedeutungen wie kleine Hindernisse in den Boden, schleudert dann wieder mit einem Wort Nichtigkeiten so steil empor, daß sie wie die höchsten Gipfel der Dinge erscheinen. (133)

Dabei behält Salten in seinem Essay überall den Abstand des Beobachters, der gegen die Verführungskunst von Luegers Redebegabung selber immun bleibt und sie im Grunde für lächerlich hält: "Im Furor seiner Rednerstunde gerät der Mutterwitz ... ins Sieden und wirft Blasen, in denen alles wie toll, alles verkehrt und lächerlich erscheint." (134) Doch macht Salten klar, daß Luegers Tiraden für die Opfer, die sie für verkehrt und lächerlich halten, gleichwohl lebensgefährlich sind. Denn Lueger "siegt mit alledem. Schlägt zu damit und trifft und wirkt. Oft schon hat er seine entsetzten, überrumpelten Gegner vor sich hergejagt - wie sich nachher gezeigt hat - mit einem Eselskinnbacken." (Ebd.) Also mit einer brutalen Gewalt, deren Opfer nicht vereinzelt sind, sondern nach tausenden

26"Die Wiedereinführung des Irrationalen war die gute Gelegenheit der menschlichen Schwäche, sich gehenzulassen, sich auszuverschenken an Instinkte, die nicht nachgeprüft werden, weil sie tief sind, und nicht nachgeprüft werden dürfen, weil ihre Tiefe sie heiligt." (Ein Zeitalter wird besichtigt, S. 133-134). 
zählen, so wie Simson mit dem Kinnbacken eines Esels in einer einzigen Aktion gleich tausend Philister erschlug.

Und nicht nur dies, sondern Salten macht ebenso klar, daß gerade auch der Antisemitismus von Anfang an ein integraler, wohlberechneter Teil von Luegers Rhetorik ist:

Da kommt dieser Mann und schlachtet - weil ihm sonst alle anderen Künste mißlangen ${ }^{27}$ - vor der aufheulenden Menge einen Juden. Auf der Rednertribüne schlachtet er ihn mit Worten, sticht ihn mit Worten tot, reißt ihn in Fetzen, schleudert ihn dem Volk als Opfer hin. Es ist seine erste monarchisch-klerikale Tat: Der allgemeinen Unzufriedenheit den Weg in die Judengassen weisen; dort mag sie sich austoben. Ein Gewitter muß diese verdorbene Luft von Wien reinigen. Er läßt das Donnerwetter über die Juden niedergehen. Und man atmet auf. (132)

Es ist selbstverständlich, daß Lueger hier nur dann als Vorläufer Hitlers erscheint, wenn man außer acht läßt, daß Salten für seinen Essay die Textsorte der Satire gewählt hat. Salten bedient sich Metaphern, die durch ihre Übertreibung wirken sollen. Lueger war also keineswegs bereits Hitler, benutzte den Antisemitismus vielmehr "nur" als Mittel zum Zweck. Sein viel zitierter Ausspruch: "Wer ein Jud ist, bestimme ich," bringt ihn in die Nähe von Heinrich Manns menschenfreundlichem Fabrikbesitzer Lauer, der ein Antisemit ist und trotzdem die Freiheit für sich beansprucht, mit dem jüdischen Kaufhausbesitzer Cohn befreundet zu sein. Lueger also dürfte die von ihm gepredigte Gewalt gegen die Juden nicht wörtlich gemeint haben, er "schlachtete" nicht mit Messern oder Kugeln oder gar mit Gas, sondern nur "mit Worten". Er vermied es aber doch andererseits auch wieder zu sagen, daß er es nicht wörtlich meine, und erreichte und prägte mit seinen Worten tatsächlich, wie unbeabsichtigt auch immer, Antisemiten wie Hitler, die den Judenmord dann wörtlich meinten und die Macht hatten, ihn durchzusetzen.

Salten läßt den von ihm vorgeschlagenen Epochenroman mit einer Szene

${ }^{27}$ Die Metapher erinnert daran, daß Hitler zu dem Entschluß, Politiker zu werden, sich erst verstieg, als er wortwörtlich mit dem Versuch gescheitert war, sich an der Kunstakademie zum Kunstmaler ausbilden zu lassen. 
enden, die das Ende des historischen Lueger enthält und für uns im Nachhinein eine merkwürdige Ähnlichkeit mit dem Ende des deutschen Reichspräsidenten Hindenburg gewinnt, also des letzten deutschen Reichspräsidenten vor der Machtergreifung der Nazis. Bei Salten lesen wir, wie die Zeit über den gealterten Lueger hinweggegangen ist und wie Lueger, der sich zum "ewig greinenden, mißlaunigen, scheltenden Alten" gewandelt hat, weiter vergeblich versucht, sich und der Welt zu beweisen, $\mathrm{da} ß$ er noch derselbe ist; wie er

mit gebrochener Stimme wieder schmettern und donnern möchte, und wie ihn dann die Weihrauchdämpfe mitleidiger Schmeichler benebeln und beschwichtigen. Das letzte Kapitel: wie diese Flamme eines Wiener Temperamentes im blassen Schimmer der Ordensterne, im kindischen Glanz von Auszeichnungen und Titeln verlöscht. (141)

Salten kalkulierte freilich allzu optimistisch, daß die sozialistisch dominierte Periode, die auf die von Lueger repräsentierte Form des österreichischen Wirtschaftsliberalismus folgen mußte, zwar das Kaiserreich auf neue Weise bedrohen, es aber deshalb doch nicht wirklich in seiner Existenz gefährden werde. Franz Josefs schließliche Bestätigung von Luegers Bürgermeisterwahl muß für ihn schon so etwas wie die Vorwegnahme der späteren Abdankung des Kaiserhauses durch Kaiser Karl am Ende des Ersten Weltkriegs gewesen sein. Da er schon mit Franz Josefs Einlenken bei der Bürgermeisterwahl Luegers in keiner Weise übereinstimmen konnte, war seine verzweifelte Hoffnung, daß das, was Franz Josef für ihn verkörperte, trotz allem irgendwie überleben müsse. Man wird deshalb verstehen, daß der Untergang der Donaumonarchie für Salten eine heftigere, existentiellere Enttäuschung bedeutete als für Heinrich Mann später die Zerstörung der Weimarer Republik durch die Nazidiktatur. Die monarchistische Überzeugung scheint in Salten auch tiefer verwurzelt gewesen zu sein als in Schnitzler, Hofmannsthal oder Beer-Hofmann, da er auf die erste sozialistische Regierung nach dem verlorenen Kriege unvergleichlich schärfer reagierte. Es ist gewiß kein Zufall, daß er sich - im Hause Schnitzler - gerade in der Gegenwart des ausgewiesenen leidenschaftlichen Monarchisten Thomas Mann zu der Forderung verstieg, man müßte die von dem Sozialdemokraten Karl 
Renner geführte Regierung, einschließlich des ersten Präsidenten der Konstituierenden Nationalversammlung und vorläufigen Staaatsoberhaupts Karl Seitz, "an die Wand stellen." Der Ausspruch war Schnitzler, der ihn notierte, im höchsten Grade peinlich. (Tagebuchaufzeichnung vom 10. 12. 1919) Zwei Tage später sah er sich, wie er wiederum in seinem Tagebuch festhielt, dazu veranlaßt, mit Richard A. Bermann über "das Problem Salten" zu reden.

Saltens Wut schlug sich dann keineswegs in politischem Radikalismus nieder. Vielmehr zog er sich politisch auf scheinbar unverfängliche Positionen zurück. Als Präsident des Österreichischen PEN wich er in den dreißiger Jahren in die bekannte, schlecht beratene, übel endende und ihm oft genug böse angerechnete Appeasementpolitik einer Vermittlerrolle gegenüber Nazi-Deutschland aus ${ }^{28}$ - und als Schriftsteller fast ganz in das Schreiben von Tierbüchern, in denen er sein konservatives Weltbild in die Form von sentimentalen Idyllen brachte. Heinrich und Thomas Mann blieben ihm zugetan. ${ }^{29}$ Es scheint auch Thomas zu verdanken gewesen zu sein, daß Schnitzler sich während seines Besuchs sogar einmal zu einem verhaltenen Lob Saltens - es findet sich gleich neben der Äußerung über "das Problem Salten" - für die drei Einakter Kinder der Freude bereit fand, auf die er zuvor mit Verachtung reagiert hatte, ${ }^{30}$ doch änderte das

${ }^{28}$ Eine dankenswert detaillierte Analyse von Saltens Rolle auf dem internationalen PEN Kongress, der vom 25. - 28. Mai 1933 in Ragusa stattfand, findet sich bei Lore Muerdel Dormer (Anm. 13), S. 413-416.

${ }^{29}$ Die Brüder Mann versuchten sich später im amerikanischen Exil für finanzielle Unterstützung des in Zürich lebenden Salten einzusetzen.

${ }^{30} \mathrm{Vgl}$. zunächst die Tagebuchnotiz vom 12. 11. 1917: "Las Salten's drei Einakter "Kinder der Freude", schlampige zum Theil theatralisch mäßig geschickte, innerlich ordinäre Arbeiten." Ein Zusatz macht deutlich, daß für Schnitzler, anders als offenbar für Heinrich Mann, ein produktives Wechselverhältnis mit dem Autor Salten keinesfalls in Betracht kam: "Manches ganz lächerlich von mir beeinflußt - wie verständlich ist sein tiefer verzweifelter und ohnmächtiger Widerstand gegen mich.-" Ähnlich am 23. 12. 1917, nachdem die Kritiken über Saltens drei Einakter "einmütiges Entzücken" geäußert hatten: "Lehrreich ein Vergleich mit den Kritiken über die "Kom[ödie] der Worte" vor 2 Jahren; wovon S[alten]s Einakter ein schwacher und ziemlich ordinärer Abklatsch (keine Copie!)." Die Eintragung vom 18. 1. 1918, nach dem Besuch der Aufführung von Kinder der Freude im Volkstheater, konstatiert erneut: "Im episodischen gute Einfälle - wo das Stück anzufangen hätte, ist es immer aus. Im ganzen eine widerwärtige Angelegenheit;- besonders die Herbot Copie in 'Lebensgefährten'." Am 12. 
im folgenden kaum etwas an Schnitzlers gewohnten Reserven gegenüber Saltens künstlerischer Begabung. Selbst positive Urteile über Salten klingen im Munde Schnitzlers abfällig oder bestenfalls herablassend, wie etwa das folgende: "amüsant und voll Talent - wenn auch nicht eigentlich dichterischem. Freute mich ihm sehr viel gutes sagen zu können; erhoffe ihm einen großen Erfolg. ${ }^{131}$

\section{III.}

So bleibt im Rückblick auf den Lueger-Essay das Bedauern, daß Salten wohl nicht zum wenigsten infolge des fehlenden Verständnisses seiner Wiener Freunde davon abgehalten wurde, sein glänzendes politischsatirisches Talent in dem Maße zu entfalten, wie es offenbar in ihm angelegt war. Mit dem Lueger-Essay hat er dem politisch-satirischen Roman einen Maßstab gesetzt, dessen Erfüllung nicht nur im österreichischen, sondern im gesamten deutschsprachigen Raum zur Zeit des Ersten Weltkriegs niemand näher gekommen scheint als er selbst in seiner Romanskizze. Das war nur möglich, weil er das von Schnitzler verfochtene Kriterium 'ausgewogener' Satire zwar theoretisch für den zukünftigen Lueger-Roman forderte, ${ }^{32}$ sich in der Praxis des Lueger-

12. 1919 jedoch, nach dem Besuch der Theateraufführung von Kinder der Freude mit Thomas Mann, ändert sich plötzlich der Ton: "Gefiel mir heute in mancher Hinsicht besser." Unter demselben Datum urteilt Thomas Mann in einer Tagebuchaufzeichnung, in der er ausdrücklich festhält, er habe im Theater mit Schnitzler gesprochen, über Kinder der Freude: "Drei Einakter von Salten, nett und nicht ohne gefühltes Leben. Ich genoB das etwas schleppende, aber abgerundete und talentvolle Spiel von Herzen." (Tagebücher, 1918-1921, hrsg. Peter de Mendelssohn, Frankfurt a.M. 1979, S. 342 ).

${ }^{31}$ Aufzeichnung vom 9. 5. 1919, anläßlich der Aufführung von Saltens Der Gemeine, nachdem die Aufführung dieses Stücks von der Zensur zwanzig Jahre lang verboten gewesen war. - $\mathrm{Zu}$ Hofmannsthals und Beer-Hofmanns Umgang mit Salten als Dichterkollegen vgl. noch einmal oben Anm. 14.

${ }^{32}$ Im ersten Absatz des Lueger-Essays heißt es: "Aber das [sc. das Schreiben des Lueger-Romans] müßte dann freilich einer tun, dem nicht $\mathrm{Haß}$, noch Bewunderung den Blick umschleiert; es müßte jemand sein, der die wundervolle Gabe des Anschauens besitzt und dem in seiner Kunst nichts höher gilt als die Anschaulichkeit." Heinrich Mann wäre also formal berechtigt gewesen, sich mit seiner neuen Selbstdeutung des Untertans ("Ich [...] suchte mein Wissen überzeugend, wenn es hoch kam, auch anwendbar zu machen.") nicht nur an Schnitzler anzuhängen, den er 
Essays aber sowenig daran hielt wie Heinrich Mann im Untertan. Auf diese Weise hat er sich das Verdienst erworben, im Wiener Bürgermeister Lueger, der in einer deutschen Enzyklopädie noch dreißig Jahre nach dem Zweiten Weltkrieg beschönigend als "nicht ohne Demagogie" operierender "volkstüm1[icher] Massenführer, bed[eutender] Kommunalpolitiker" gekennzeichnet wird, ${ }^{33}$ den modernen Massenverführer und Vorläufer Hitlers erfahrbar gemacht zu haben. ${ }^{34}$

Richtig zu würdigen ist das aber nur im Zusammenhang mit Saltens zweitem Verdienst. Hat er doch in Lueger nicht nur den Diktator in nuce,

ausführlich würdigt, sondern paradoxerweise auch an Saltens im LuegerEssay entworfenes Programm. Da Salten sich aber im Essay selber nicht daran gehalten hatte, ist es nur folgerichtig, daß in Heinrich Manns Autobiographie Ein Zeitalter wird besichtigt zwar der Name Lueger, nicht aber der Name Salten vorkommt.

${ }^{33}$ Mayers Enzyklopädisches Lexikon, XV, 1975, S. 300-301.

${ }^{34}$ Man hat die Bedeutung Luegers für Hitler oft mit dem Hinweis auf den radikaleren Antisemitismus Georg von Schönerers heruntergespielt. Hitler selbst berief sich aber im dritten Kapitel von Mein Kampf auf Lueger mehr als auf Schönerer, denn es war Lueger, von dem er nach eigener Aussage für seine politische Karriere am meisten gelernt hatte. Nämlich for allem das Verfahren, den Antisemitismus als Mittel einer Politik einzusetzen, mit der die Massen zu gewinnen waren. (So auch, mit einem eigenen Kapitel über Lueger, jüngst Brigitte Hamann: Hitlers Wien. Lehrjahre eines Diktators. München 1996.) In Mein Kampf hatte Hitler an Schönerer auszusetzen, daß er die Auseinandersetzungen weitgehend im Parlament auszutragen suchte und sich dabei nicht auf die breite Masse, sondern ("bürgerlich, vornehm, gedämpft radikal", S. 111) nur auf die Bürger stützte - nach Hitler der wichtigste Grund dafür, warum Schönerer es nicht schaffte, eine mächtige alldeutsche Partei aufzubauen. Lueger dagegen, dessen Antisemitismus er zunächst mit Unverständnis, dann aber mit wachsendem Verständnis begegnet sei, rühmte er gerade wegen seiner Fähigkeit, der Christlichsozialen Partei über die breite Masse (zumal "des kleinen und unteren Mittelund Handwerkerstandes", S. 130), mit seiner außerhalb des Parlaments eingesetzten Redegewalt zu einer für damalige Verhältnisse ungeheuren Macht verholfen zu haben. Sein Ehrgeiz sei allerdings nicht weit genug gegangen, da er sich mit der Herrschaft über Wien begnügt habe, statt den unverzeihlicherweise deutschfeindlichen Habsburgern die Herrschaft über ganz Österreich zu entreißen. Obendrein seien die Christlich-Sozialen törichterweise bei einem Antisemitismus auf unwissenschaftlicher, nämlich konfessioneller Grundlage steckengeblieben, wo ein eindeutig rassischer Antisemitismus der Partei über ihre lokale Begrenztheit hinausgeholfen und Österreich und Deutschland den verlorenen Weltkrieg erspart hätte. (Mein Kampf, München 1940, S. 58ff und S. 107-137). 
sondern auch schon den rücksichtslosen Technokraten vorgeführt. Für Dr. Karl Lueger, das macht Salten ganz klar, hat die funktionale und effektive Planung nach Sachzwängen Vorrang vor sozialen Lösungen, die er ihrerseits propagandistisch - das besorgt schon der Name seiner Partei - als automatisch zu erwartendes Produkt seiner Sachplanungen auszugeben versucht. Für Salten steht der Erfolg des Technokraten Lueger außer Frage - aber ebenso die Problematik dieses Erfolges:

Und nun hat er Wien aufgerichtet als eine Art von Königtum mitten in Österreich. Dutzendweise wurden die kleinen Ortschaften, welche Wien umgürteten, von dem großen Gemeinwesen verschlungen. Das ist jetzt, vom Marchfeld bis zur Sophienalpe, nur mehr eine einzige Stadt: Wien. Und in dieser Stadt ein einziges Haupt: Lueger, der Bürgermeister. Er nahm die Straßenbahnen, die Gaswerke, das elektische Licht, die Leichenbestattung, die Spitäler. Wasser und Feüuer, Leben und Tod gehört seiner Stadt. All dies lag freilich in der Entwicklung, hätte auch unter einer andern Verwaltung so kommen müssen. Aber er nahm diese Dinge, unter lauten pathetischen Proklamationen, er nahm sie wie man eroberte Provinzen einnimmt, und er schuf aus all diesen Besitztümern neue Werkzeuge seiner Macht. Wo die Straßenbahn hingeführt wird, das elektrische Licht, die Wasserleitung, da steigen in den entlegensten Gegenden die Bodenpreise, hebt sich der Wohlstand. Treue Bezirke können belohnt, unsichere gekirrt, treulose bestraft werden. Die Stadt, die so viele Betriebe in ihrer Hand hält, herrscht über eine Armee von Dienern, Arbeitern, Beamten, Lehrern, Ärzten und Professoren, herrscht durch tausendfach verknüpfte Interessen weithin über die Gesinnungen, und allen ist der Bürgermeister, von dem sie abhängen, wie ein Monarch. (Das österreichische Antlitz, S. 137-138)

Heinrich Mann stimmte hier offenbar völlig mit Saltens politischer Bewertung des Wiener Bürgermeisters überein und adaptierte sie für seinen deutschen Helden. Fast bekommt man den Eindruck, als suchte Heßling zu Beginn seiner Karriere bewußt nach Vorbildern, die dem Technokraten Lueger möglichst ähnlich sein sollten. Im 3. Kapitel will er im alten Buck, der seinem Vater zu dem für die Papiermühle nötigen Wasser 
verholfen hat, nicht den für das Allgemeinwohl wirkenden Gemeindepolitiker, sondern unbedingt einen belohnenden und kirre machenden technokratischen Machtmenschen bewundern. Als er sieht, daß er sich darin in Buck getäuscht hat, hält er dennoch umso fester für sich selbst an der gewählten Rolle fest, und er wächst mehr und mehr in sie hinein. Nach dem zweiten Prozeß, der zur Verurteilung des alten Buck führt, steigt er schließlich mit Hilfe der Aktienmehrheit selber zum Generaldirektor von Gausenfeld auf. (327) So wichtig wie für den ersten Prozeß der Antisemitismus, so wichtig ist für den zweiten das Thema des Verhältnisses von Besitz und Macht, und es wird deutlich, daß für den Karrieristen Heßling die Macht in Wahrheit wichtiger ist als der Besitz. Genau wie für Lueger fallen auch für Heßling Fortschritt und Karriere zusammen, und wie sich schon Lueger an das vulgärdarwinistische Prinzip hält, daß Gewinner, um gewinnen zu können, Verlierer brauchen, so betreibt Heßling seine Machtkarriere immer wieder neu als Vernichtungskrieg. ${ }^{35}$

Dabei bieten weder Salten noch Heinrich Mann ihre satirische Kritik ohne positive Folie. Auf Saltens Monarchismus, der uns heute politisch naiv erscheint, wurde oben bereits hingewiesen. Es wäre aber verkehrt, im Falle Heinrich Manns einfach auf seine Demokratiegläubigkeit zu verweisen und in ihr einen Beweis für die größere politische Weisheit zu sehen. Auf Demokratie wird im Roman nirgends direkt abgehoben. Statt dessen stellt Heinrich Mann dem Ausbeuter und Karrieristen Heßling als

\footnotetext{
${ }^{35}$ Im dritten Kapitel beendet Heßling seine Auseinandersetzung mit dem Maschinenmeister Napoleon Fischer "augenrollend" mit dem Ausspruch: "[...] denn so viel weiß ich, daß einer von uns beiden - auf dem Platze bleiben wird." (S. 86) Nach dem Gespräch mit dem alten Buck sagt er sich, indem er die Faust in der Tasche ballt: "Vorläufig muß man sich noch mit ihm verhalten, aber wehe, wenn ich der Stärkere bin!" (S. 91) Später, im fünften Kapitel, ist er dann doch bereit zu einem Bündnis mit Napoleon Fischer. Da "blitzt" er nicht, sondern beide "Bundesgenossen [lachen] vor Vergnügen" bei der Vorstellung, daß sie nicht nur die Liberalen - und das heißt für Heßling zunächst vor allem den Konkurrenten Buck - aus der Stadtverwaltung drängen werden. Das gemeinsame Ziel geht erheblich weiter: "Die bürgerliche Demokratie [...] die vermöbeln wir auch noch!" (S. 247) Doch sieht Heßling dieses Bündnis dann gleichwohl nur auf Zeit und verliert nicht aus dem Auge, daß Napoleon Fischer für ihn in Wahrheit ein gleichfalls aus dem Wege zu räumender Feind bleibt: ''Aber' - er schüttelte die Faust gegen die Zimmerdecke - 'wir sprechen uns wieder. Und wenn es zehn Jahre dauert, die Abrechnung kommt!'" (S. 248).
} 
Vorbildgestalten die beiden geschäftlich erfahrenen und zugleich menschlichen Geschäftsleute Sötbier und Buck gegenüber, die nicht an eigenem Fehlverhalten, sondern an den unsoliden Geschäftspraktiken Heßlings scheitern. Offenbar hat Heinrich Mann in Sötbier und im alten Buck seinem eigenen Vater, dem Lübecker Kaufmann und Senator, ein aus Ehrerbietung diktiertes literarisches Doppeldenkmal gesetzt. ${ }^{36}$

Das Ideal kaufmännischer Gediegenheit, mit dem Heinrich Mann hier umstandslos hinter die marxistische Klassenkampftheorie zurückgreift, scheint heute nach dem weltweiten Zusammenbruch der marxistisch orientierten Ideologien und Systeme wieder neue Aufmerksamkeit zu verdienen. Der mittlerweile nahezu global an die Macht gekommene Glaube an die Allheilkraft von Technokratie und Managertum wird zunehmend als Gefahrenquelle für neue Unmenschlichkeit durchschaubar. Angesichts der überwältigenden Vorherrschaft heutiger Managerideologie wirkt jedoch Heinrich Manns altfränkisches Ideal kaufmännischer Gediegenheit kaum weniger naiv als die verzweifelte Hoffnung, die Salten auf das Fortbestehen des österreichischen Kaiserreichs setzte. ${ }^{37}$

${ }^{36}$ Es genügt hier, daran zu erinnern, daß Heinrich Mann in Ein Zeitalter wird besichtigt, im Kapitel über seinen Bruder Thomas und dessen Voraussetzungen, den Vater mit deutlicher innerer Zustimmung, ja mit Stolz, folgendermaßen kennzeichnet: "Der Kaufmann legte Wert auf unbezahlte Arbeiten, die gemeinnützig dienten. Die Steuerpflichtigen seines Stadtstaates kosteten ihn mehr Mühe und Zeit, als ein Mitglied des regierenden Senates ersetzt bekam. Ich glaube nicht, daß er, obwohl fünfundzwanzig Jahre Chef der Firma, ihr Vermögen vermehrt hat." (S. 152).

${ }^{37}$ Der österreichische Kaiser scheint für Salten auf ähnliche Weise Vaterstelle eingenommen zu haben, wie für den späten Heinrich Mann der leibliche Vater. Im Essay über Franz Josef in der Sammlung Das österreichische Antlitz schreibt Salten, daß dieser Kaiser mit seinem "sanften Lächeln" für ihn das 'Vornehme' am Österreichischen verkörpere: "Die Wiener, die vornehmen wenigstens, diejenigen die das Walzertum Schuberts, Lanners und der Strauß-Walzer repräsentieren, die waren wie er [sc. Franz Josef]" (S. 276). Natürlich diente die Aufzählung der Musiker hier nur dazu, das mögliche Mißverständnis auszuräumen, mit dem Begriff des Vornehmen sei der herrschende Adel gemeint. (In der Sammlung Das österreichische Antlitz ist der Essay "Aristokraten-Vorstellung" neben dem Lueger-Essay der einzige mit eindeutig satirischer Tendenz.) In Wahrheit sah Salten in dem berühmten "sanften Lächeln" des Kaisers, "das man bis in späte Tage das Lächeln Franz Josefs nennen wird," nicht Walzerseligkeit am Werke, sondern die Fürsorge, mit der sich der Kaiser in seinem Kampf gegen die Bürgermeisterwürde des Antisemiten Lueger auf die Seite der Opfer gestellt hatte. 
Der aus beiden Texten abzulesenden positiven Utopie tut indessen die politische Naivität ihrer Autoren keinen Abbruch. Beide warnen einleuchtend vor den menschlichen Folgelasten einer auf Macht und Karriere fixierten Technokratie für die erklärten Verlierer. Saltens Essay aber weist darüber hinaus auf die Gefahren hin, die dem jeweiligen politischen System als solchen drohen, wenn vor dem Hintergrund wachsender sozialer Ungerechtigkeiten aus Technokraten Volksverführer werden. In einer Zeit, in der Fremdenhaß und Antisemitismus immer noch alles andere als tot sind, lohnt es sich offenbar nicht nur aus historischen Gründen, über Heinrich Manns Roman sein wichtigstes literarisches Modell, ${ }^{38}$ den Lueger-Essay, nicht zu vergessen.

${ }^{38}$ Natürlich sind auch andere Modelle von Interesse. Vgl. zuletzt den informativen Beitrag von Peter Sprengel: "Kaiser und Untertan. Zur Genese von Heinrich Manns Roman" in: Heinrich-Mann-Jahrbuch, Bd. 10 (1992), S. 57-73. Sprengel verweist auf Ludwig Thomas Analyse von Wilhelm II. Kaiserreden im Eröffnungsheft der Zeitschrift März (Januar 1907). Die aus Thomas Aufsatz abziehbare "Grundidee von Heinrich Manns Roman" ist jedoch für eine angemessene Bewertung der politischen Satire des Romans weit weniger geeignet als Saltens Lueger-Essay: "Die Affinität des zeitkritischen Ansatzes Heinrich Manns mit demjenigen Thomas [...] hat ihre Grundlage in der gemeinsamen Philisterkritik." (S. 59). 